\title{
Nutritional and chemical characterization of edible petals and corresponding infusions: Valorization as new food ingredients
}

\author{
Tânia C.S.P. Pires ${ }^{a}$, Maria Inês Dias ${ }^{a}$, Lillian Barros ${ }^{a, b}$, Isabel C.F.R. Ferreira ${ }^{a, *}$ \\ ${ }^{a}$ Mountain Research Center (CIMO), ESA, Polytechnic Institute of Bragança, Campus de Santa Apolónia, 1172, 5300-253 Bragança, Portugal \\ ${ }^{\mathrm{b}}$ Laboratory of Separation and Reaction Engineering (LSRE), Associate Laboratory LSRE/LCM, Polytechnic Institute of Bragança, Campus de Santa Apolónia, 1134, 5301-857 \\ Bragança, Portugal
}

\section{A R T I C L E I N F O}

\section{Article history:}

Received 31 May 2016

Received in revised form 17 August 2016

Accepted 6 October 2016

Available online 6 October 2016

\section{Keywords:}

Edible petals

Infusions

Nutritional value

Chemical composition

\begin{abstract}
A B S T R A C T
Edible flowers provide new colours, textures and vibrancy to any dish, and apart from the "glam" factor, they can constitute new sources of bioactive compounds. In the present work, the edible petals and infusions of dahlia, rose, calendula and centaurea, were characterized regarding their nutritional value and composition in terms of hydrophilic and lipophilic compounds. Carbohydrates were the most abundant macronutrients, followed by proteins and ash. Fructose, glucose and sucrose were identified in all the petals and infusions. Rose petals and calendula infusions gave the highest content of organic acids, mainly due to the presence of malic and quinic acids, respectively. Polyunsaturated fatty acids predominated over saturated fatty acids, mainly due to the contribution of linoleic acid. Calendula presented the highest content in tocopherols, with $\alpha$-tocopherol as the most abundant. These results highlight the interest of edible petals "as" and "in" new food products, representing rich sources of bioactive nutrients.
\end{abstract} (c) 2016 Elsevier Ltd. All rights reserved.

\section{Introduction}

Consumption habits are becoming more diversified and directed towards more sustainable food options (Falguera, Aliguer, \& Falguera, 2012). The range of plant species used for food is also becoming more varied, seeking to combine new ingredients with some potential health benefits, that could improve the health of the consumers but also with a major importance in ecological sustainability (Leonti, 2012). This search for new food products is also a pursuit for new colours, textures and flavours that can be achieved with the use of edible flowers, such as has been done by several restaurant chefs worldwide (Kelley, Behe, Biernbaum, \& Poff, 2001; Łuczaj et al., 2012); leading to the recovery of earlier lifestyles in which flower cookery had an important role in old civilizations (Cunningham, 2015; Rop, Mlcek, Jurikova, Neugebauerova, \& Vabkova, 2012).

Apart from the "glam" factor, edible flowers have important nutritional characteristics and can constitute new sources of bioactive compounds (Lara-Cortés et al., 2014; Mlcek \& Rop, 2011). They represent an unexplored niche market with great economic and social importance being used since ancient times in culinary preparations, such as sauces, liquors, salads and

\footnotetext{
* Corresponding author.

E-mail address: iferreira@ipb.pt (I.C.F.R. Ferreira).
}

desserts (Koike et al., 2015; Mlcek \& Rop, 2011), and also in the preparation of hot beverages (tisane and infusion), mainly in European countries, due to their medicinal properties (NavarroGonzález, González-Barrio, García-Valverde, Bautista-Ortín, \& Periago, 2015). In ancient Rome, various species of rose flowers (Rosa spp.) were used to prepare purée and omelets (Cunningham, 2015). In Medieval France, the flowers of calendula (Calendula officinalis L.) were used to prepare omelets but also salads or as an accompaniment cheese (Lara-Cortés et al., 2014). In Mexico, Dahlia flowers are commonly consumed in different type of dishes, for example in dried soups (Lara-Cortés et al., 2014).

The composition on proteins, vitamins, fat and carbohydrates of flowers is not very distinct from other parts of the plant, however protein and fat content are considered to be low (NavarroGonzález et al., 2015); water represents more than $80 \%$ of the flower composition, and carotenoids, phenolic compounds and essential oils have been the most studied bioactive compounds (Navarro-González et al., 2015; Rop et al., 2012). Edible flower consumption is being encouraged, through the sell of packed bunches and boxes, and also through dietary supplements, functional ingredients, and additives (Loizzo et al., 2016; Rop et al., 2012). The innumerous phytochemicals present in edible flowers are related to their health benefits, such as antioxidant, anti-inflammatory, anti-cancer, anti-obesity, hypoglycemic, neuro, hepatic and gastro protective properties (Cunningham, 2015; Loizzo et al., 2016; Lu, Li, \& Yin, 2016). 
In particular, the nutritional and chemical composition of rose (Rosa canina L.) and calendula flowers have already been studied (Barros, Carvalho, \& Ferreira, 2011; Miguel et al., 2016), also the fatty acids composition of calendula seeds oils (Dulf, Pamfil, Baciu, \& Pintea, 2013) and the crude protein of centaurea (Centaurea cyanus L.) flowers (Rop et al., 2012). Despite the existence of some publications regarding edible flowers, it is important to compare their potential to be used in different forms, namely as fresh produces or in infusion preparations. Therefore, in the present work, edible petals of different species (dahlia, rose, calendula and centaurea) were characterized in terms of macronutrients composition, energetic value, fatty acids, soluble sugars, organic acids and tocopherols, and compared to the nutritional composition of their infusions.

\section{Materials and methods}

\subsection{Standards and reagents}

HPLC grade acetonitrile, $n$-hexane and ethyl acetate were from Fisher Scientific (Lisbon, Portugal). A reference standard mixture (standard 47885-U) for fatty acids methyl ester (FAME) was purchased from Sigma (St. Louis, MO, USA), as also other standards: $\alpha$ - and $\delta$-tocopherols, sugars and organic acids. The isoforms $\beta$ - and $\gamma$-tocopherols and tocol $(50 \mathrm{mg} / \mathrm{ml})$ were purchased from Matreya (Pleasant Gap, PA, USA). All other general laboratory reagents were purchased from Panreac Química S.L.U. (Barcelona, Spain) and water was treated in a Milli-Q water purification system (TGI Pure Water Systems, USA).

\subsection{Samples and infusion preparation}

The samples were kindly supplied by RBR Foods, a farming company producer of fruits and flowers from Castro Daire (Portugal), as dry material to be used directly or for infusion's preparation. Petals of four different species were used in the present study: Dahlia mignon (commercial seeds mixture), Rosa damascena 'Alexandria' and $R$. gallica 'Francesa' draft in $R$. canina, Calendula officinalis $\mathrm{L}$. and Centaurea cyanus L. (Fig. 1). These samples are designated throughout the manuscript by their common names: dahlia, rose, calendula and centaurea, respectively. All the samples were reduced to a fine powder (20 mesh) and mixed to obtain homogenate samples.

For infusions preparation, boiling distilled water $(100 \mathrm{ml})(\mathrm{pH}$ 6.6) at $100{ }^{\circ} \mathrm{C}$ was added to each sample (500 mg) and left to stand at room temperature for $5 \mathrm{~min}$. Afterwards, the infusions were filtered under reduced pressure $(0.22 \mu \mathrm{m})$ and stored at $-5^{\circ} \mathrm{C}$ (1 week) until further analysis.

\subsection{Nutritional value-proximate composition and energetic value}

The samples (dried powdered petals) were analyzed for proteins, fat, carbohydrates and ash according to the AOAC (Association of Official Analytical Chemists) procedures (AOAC, 2005). The crude protein content $(\mathrm{N} \times 6.25)$ was estimated by the macro-Kjeldahl method (AOAC, 991.02); the crude fat (AOAC, 989.05) was determined by extracting a known weight of powdered sample with petroleum ether, using a Soxhlet apparatus; the ash content (AOAC, 935.42) was determined by incineration

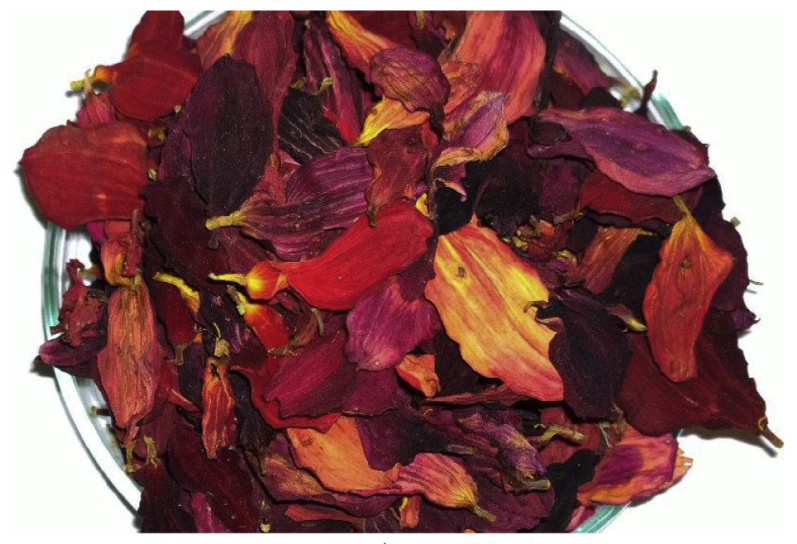

A

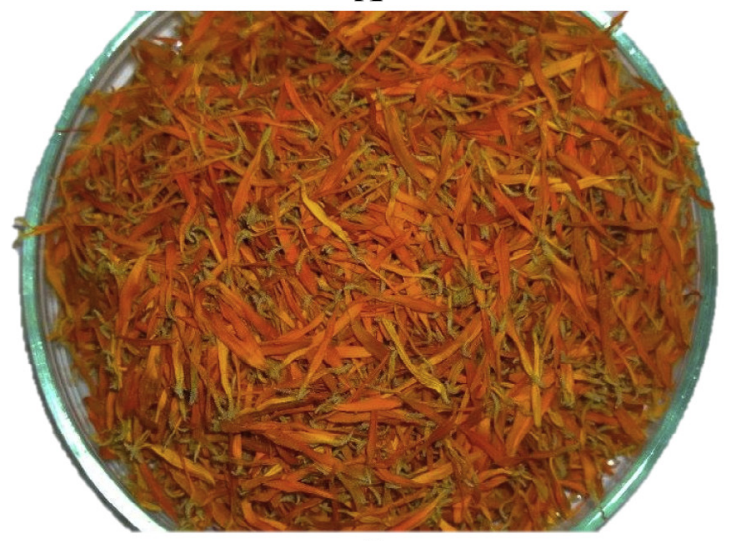

C

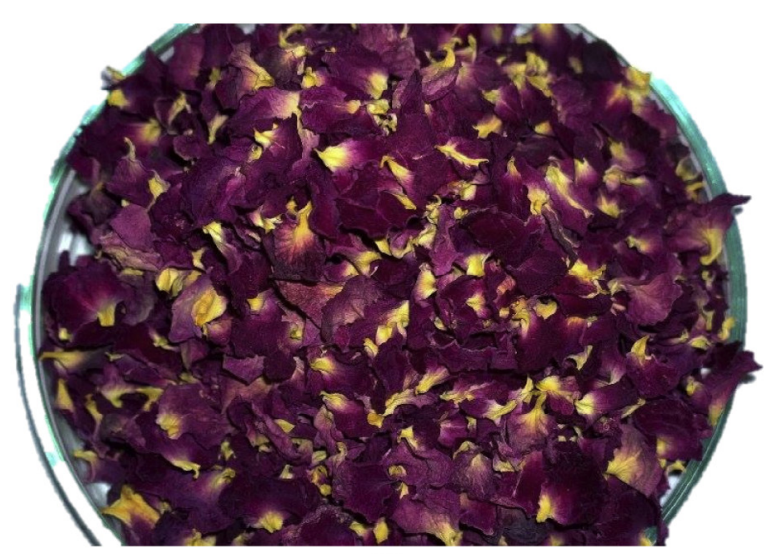

B

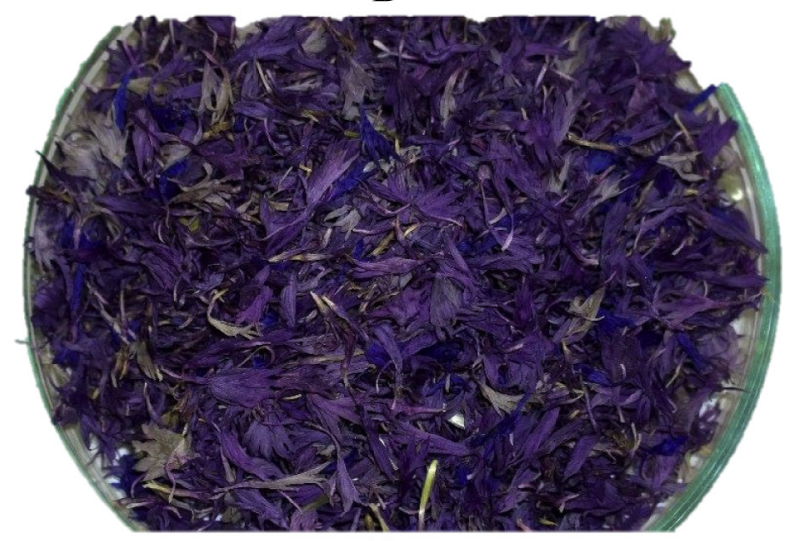

D

Fig. 1. Petals from (A) Dahlia; (B) Rose; (C) Calendula; (D) Centaurea. 
at $550 \pm 15^{\circ} \mathrm{C}$. Total carbohydrates (including fibre) were calculated by difference [Total carbohydrates $(\mathrm{g} / 100 \mathrm{~g})=100-$ ( $g$ fat $+g$ protein $+g$ ash $)]$. Total energy was calculated according to the following equation: Energy $(\mathrm{kcal} / 100 \mathrm{~g})=4 \times(\mathrm{g}$ proteins + $\mathrm{g}$ carbohydrates $)+9 \times(\mathrm{g}$ fat $)$. For infusions, total carbohydrates were calculated on the basis of total soluble sugars (Section 2.4.1) and the energetic value was calculated taking into account those results.

\subsection{Hydrophilic compounds}

\subsubsection{Soluble sugars}

Soluble sugars in dried powdered petals and infusions were determined according to a previously described procedure (Barros et al., 2013), using high performance liquid chromatography system coupled to a refraction index detector (HPLC-RI; Knauer, Smartline system 1000, Berlin, Germany). The quantification was performed using the internal standard (melezitose) method or external standard method for infusions. The results were expressed in $\mathrm{g}$ per $100 \mathrm{~g}$ of plant dry weight or in $\mathrm{g}$ per $100 \mathrm{ml}$ of infusion.

\subsubsection{Organic acids}

Organic acids were determined in dried powdered petals and infusions by ultra-fast liquid chromatography coupled to photodiode array detector (UFLC-PDA; Shimadzu Coperation, Kyoto, Japan), according to the previously described procedure (Barros, Pereira, \& Ferreira, 2013). The quantification was performed by comparison of the peak area recorded at $215 \mathrm{~nm}$ as the preferred wavelength. The results were expressed in $\mathrm{g}$ per $100 \mathrm{~g}$ of plant dry weight or in $\mathrm{mg}$ per $100 \mathrm{ml}$ of infusion.

\subsection{Lipophilic compounds}

\subsubsection{Fatty acids}

Fatty acids were determined by GC-FID (DANI model GC 1000 instrument, Contone, Switzerland), using dried powdered petals and after a trans-esterification process, according to the previously described procedure (Barros et al., 2013). The results were expressed in relative percentage of each fatty acid.

\subsubsection{Tocopherols}

The four isoforms of tocopherols were determined in dried powdered petals, according to the previously described procedure (Barros et al., 2013), using HPLC (Knauer, Smartline system 1000, Berlin, Germany) coupled to a fluorescence detector (FP-2020; Jasco, Easton, MD, USA), the quantification was based on the fluorescence signal response of each standard, using the internal standard (tocol) method or external standard method for infusions. The results were expressed in mg per $100 \mathrm{~g}$ of dry plant weight.

\subsection{Statistical analysis}

Three samples were used for each species and all the assays were carry out in triplicate. Results were expressed as mean values and standard deviation (SD) and analyzed using one-way analysis of variance (ANOVA) followed by Tukey's HSD Test with $\alpha=0.05$. This analysis was carried out using IBM SPSS Statistics for Windows, Version 22.0. (IBM Corp., Armonk, New York, USA).

\section{Results and discussion}

3.1. Proximate composition and energetic value of edible petals and corresponding infusions

Data on the nutritional composition and energetic value of edible petals from four different species-dahlia, rose, calendula and centaurea-, and of the corresponding infusions are shown in Table 1.

Carbohydrates were the most abundant macronutrients in all the dried petals, followed by proteins and ash in dahlia (5.93 and $5.83 \mathrm{~g} / 100 \mathrm{~g} \mathrm{dw}$, respectively), rose (7.58 and $4.29 \mathrm{~g} / 100 \mathrm{~g} \mathrm{dw}$, respectively) and centaurea $(5.79$ and $5.68 \mathrm{~g} / 100 \mathrm{~g} \mathrm{dw}$, respectively). Rop et al. (2012) presented lower values of crude protein in $C$. officinalis flowers $(0.673 \mathrm{~g} / 100 \mathrm{~g})$ originated from Czech Republic. Calendula petals presented a higher amount of fat $(5.33 \mathrm{~g} / 100 \mathrm{~g} \mathrm{dw})$ and ash $(6.93 \mathrm{~g} / 100 \mathrm{~g} \mathrm{dw})$ when compared to the other samples, and also a higher energetic contribution $(421.58 \mathrm{kcal} / 100 \mathrm{~g})$. These results are in accordance with the ones described by Miguel et al. (2016) who reported similar values of fat and energy in calendula flowers. Dias et al. (2014) described higher fat $(6.56 \mathrm{~g} / 100 \mathrm{~g} \mathrm{dw})$ content in dried flowers of Taraxacum sect. Ruderalia. Regarding the infusions, rose and dahlia samples presented the highest contribution in carbohydrates $(0.19 \mathrm{mg} / 100 \mathrm{ml})$, and also the highest energetic value $(0.80$ and $0.76 \mathrm{kcal} / 100 \mathrm{ml}$, respectively). Pereira, Barros, and Ferreira (2015) reported lower energy values and carbohydrates content $(0.060 \mathrm{kcal} / 100 \mathrm{ml}$ and $0.015 \mathrm{~g} / 100 \mathrm{ml}$, respectively) in the infusions of Chamaemelum nobile L., and also lower amounts of sugars, though having a similar profile (fructose, glucose and sucrose). In the same study, no sugars were detected in the infusions of Gomphrena globosa, G. globosa var. albiflora, G. haageana and Gomphrena sp., and consequently, carbohydrates content and energetic value could not be calculated.

\subsection{Hydrophilic compounds of edible petals and corresponding infusions}

Soluble sugars and organic acids composition of the studied dried petals and corresponding infusions is presented in Table 2 and Fig. 2. Dahlia and rose dried petals (10.24 and $10.75 \mathrm{~g} / 100 \mathrm{~g} \mathrm{dw})$

Table 1

Proximate composition and energy of dried petals and corresponding infusions (mean \pm SD)

\begin{tabular}{|c|c|c|c|c|c|c|c|c|}
\hline & \multicolumn{4}{|c|}{ Dried petals (g/100 g dw) } & \multicolumn{4}{|c|}{ Infusions (g/100 ml infusion) } \\
\hline & Dahlia & Rose & Calendula & Centaurea & Dahlia & Rose & Calendula & Centaurea \\
\hline \multicolumn{9}{|l|}{ Nutritional value } \\
\hline Fat & $2.23 \pm 0.05 b$ & $2.01 \pm 0.04 b$ & $5.33 \pm 0.45 a$ & $0.140 \pm 0.001$ & nd & nd & nd & nd \\
\hline Proteins & $5.93 \pm 0.2 b c$ & $7.58 \pm 0.84 a$ & $6.43 \pm 0.68 b$ & $5.79 \pm 0.1 c$ & nd & nd & nd & nd \\
\hline Ash & $5.83 \pm 0.04 b$ & $4.29 \pm 0.1 \mathrm{~d}$ & $6.93 \pm 0.14 a$ & $5.68 \pm 0.13 c$ & np & np & np & $\mathrm{np}$ \\
\hline \multirow[t]{2}{*}{ Total available carbohydrates } & $86.02 \pm 0.2 b$ & $86.12 \pm 0.8 b$ & $81.32 \pm 0.75 c$ & $88.39 \pm 0.13 a$ & $0.19 \pm 0.02 a$ & $0.19 \pm 0.01 \mathrm{a}$ & $0.17 \pm 0.01 b$ & $0.14 \pm 0.01 c$ \\
\hline & \multicolumn{4}{|c|}{ Dry petals (kcal/100 g dw) } & \multicolumn{4}{|c|}{ Infusions (kcal/100 mL infusion) } \\
\hline Energy & $387.83 \pm 0.37 c$ & $392.87 \pm 0.58 b$ & $421.58 \pm 3.54 a$ & $377.99 \pm 0.50 \mathrm{~d}$ & $0.76 \pm 0.08 a$ & $0.80 \pm 0.08 a$ & $0.68 \pm 0.02 b$ & $0.56 \pm 0.04 c$ \\
\hline
\end{tabular}

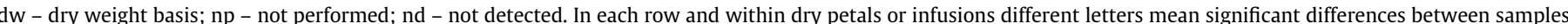
$(\mathrm{p}<0.05)$, where "a" and "d" correspond to the highest and lowest values, respectively. 
Table 2

Soluble sugars and organic acids composition in dried petals and corresponding infusions (mean \pm SD).

\begin{tabular}{|c|c|c|c|c|c|c|c|c|}
\hline & \multicolumn{4}{|c|}{ Dried petals ( $\mathrm{g} / 100 \mathrm{~g} \mathrm{dw})$} & \multicolumn{4}{|c|}{ Infusions (mg/100 ml) } \\
\hline & Dahlia & Rose & Calendula & Centaurea & Dahlia & Rose & Calendula & Centaurea \\
\hline \multicolumn{9}{|l|}{ Soluble sugars } \\
\hline Fructose & $3.87 \pm 0.23 b$ & $5.14 \pm 0.48 a$ & $1.47 \pm 0.12 c$ & $0.65 \pm 0.04 d$ & $0.10 \pm 0.01 \mathrm{a}$ & $0.10 \pm 0.01 \mathrm{a}$ & $0.066 \pm 0.001 b$ & $0.07 \pm 0.004 b$ \\
\hline Glucose & $3.23 \pm 0.25 a$ & $3.23 \pm 0.41 \mathrm{a}$ & $0.61 \pm 0.07 b$ & $0.47 \pm 0.02 b$ & $0.079 \pm 0.02 \mathrm{a}$ & $0.064 \pm 0.004 b$ & $0.021 \pm 0.001 c$ & $0.04 \pm 0.001 \mathrm{~d}$ \\
\hline Sucrose & $3.14 \pm 0.15 a$ & $2.39 \pm 0.17 b$ & $1.53 \pm 0.18 c$ & $0.38 \pm 0.01 d$ & $0.016 \pm 0.001 c$ & $0.035 \pm 0.001 b$ & $0.078 \pm 0.001 \mathrm{a}$ & $0.03 \pm 0.01 b$ \\
\hline Sum & $10.24 \pm 0.62 \mathrm{a}$ & $10.75 \pm 1.05 a$ & $3.61 \pm 0.37 b$ & $1.5 \pm 0.1 c$ & $0.19 \pm 0.02 \mathrm{a}$ & $0.19 \pm 0.01 \mathrm{a}$ & $0.17 \pm 0.01 b$ & $0.14 \pm 0.01 c$ \\
\hline \multicolumn{9}{|l|}{ Organic acids } \\
\hline Oxalic acid & $0.23 \pm 0.01 c$ & $0.26 \pm 0.01 b$ & $0.702 \pm 0.002 a$ & $0.18 \pm 0.01 d$ & $\operatorname{tr}$ & $1.31 \pm 0.01$ & $\operatorname{tr}$ & $\operatorname{tr}$ \\
\hline Quinic acid & $0.466 \pm 0.003 b$ & $1.52 \pm 0.01 \mathrm{a}$ & $0.35 \pm 0.01 b$ & nd & nd & $9.33 \pm 0.41 b$ & $14.5 \pm 0.3 a$ & $7.4 \pm 0.3 c$ \\
\hline Malic acid & $0.74 \pm 0.01 c$ & $1.23 \pm 0.02 \mathrm{a}$ & $1.14 \pm 0.02 b$ & nd & nd & $4.1 \pm 0.4 a$ & $1.16 \pm 0.15 b$ & $\operatorname{tr}$ \\
\hline Shiquimic acid & $0.0497 \pm 0.0003 c$ & $0.062 \pm 0.001 b$ & nd & $0.108 \pm 0.001 \mathrm{a}$ & $\operatorname{tr}$ & $0.368 \pm 0.001 b$ & $\operatorname{tr}$ & $1.05 \pm 0.003 a$ \\
\hline Citric acid & nd & $1.2 \pm 0.1$ & nd & nd & nd & nd & nd & $15.5 \pm 0.5$ \\
\hline Succinic acid & nd & nd & $1.77 \pm 0.03$ & nd & nd & nd & $11.2 \pm 0.5$ & nd \\
\hline Fumaric acid & $\operatorname{tr}$ & $0.011 \pm 0.001$ & $\operatorname{tr}$ & $\operatorname{tr}$ & nd & $\operatorname{tr}$ & $\operatorname{tr}$ & $\operatorname{tr}$ \\
\hline Sum & $1.49 \pm 0.01 c$ & $4.26 \pm 0.13 a$ & $3.98 \pm 0.02 b$ & $0.29 \pm 0.01 \mathrm{~d}$ & $\operatorname{tr}$ & $15.01 \pm 0.1 \mathrm{c}$ & $26.9 \pm 0.3 a$ & $23.9 \pm 0.8 b$ \\
\hline
\end{tabular}

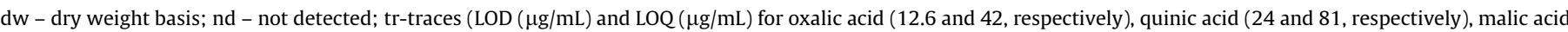

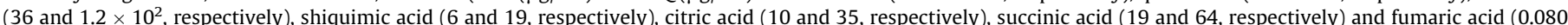

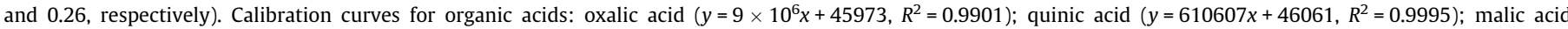

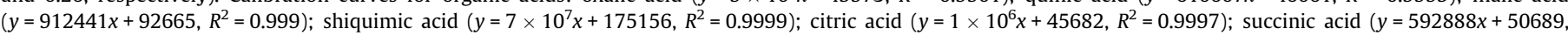

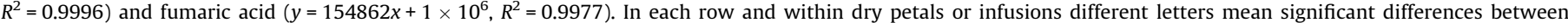
samples ( $\mathrm{p}<0.05$ ), where "a" and "d" correspond to the highest and lowest values, respectively.

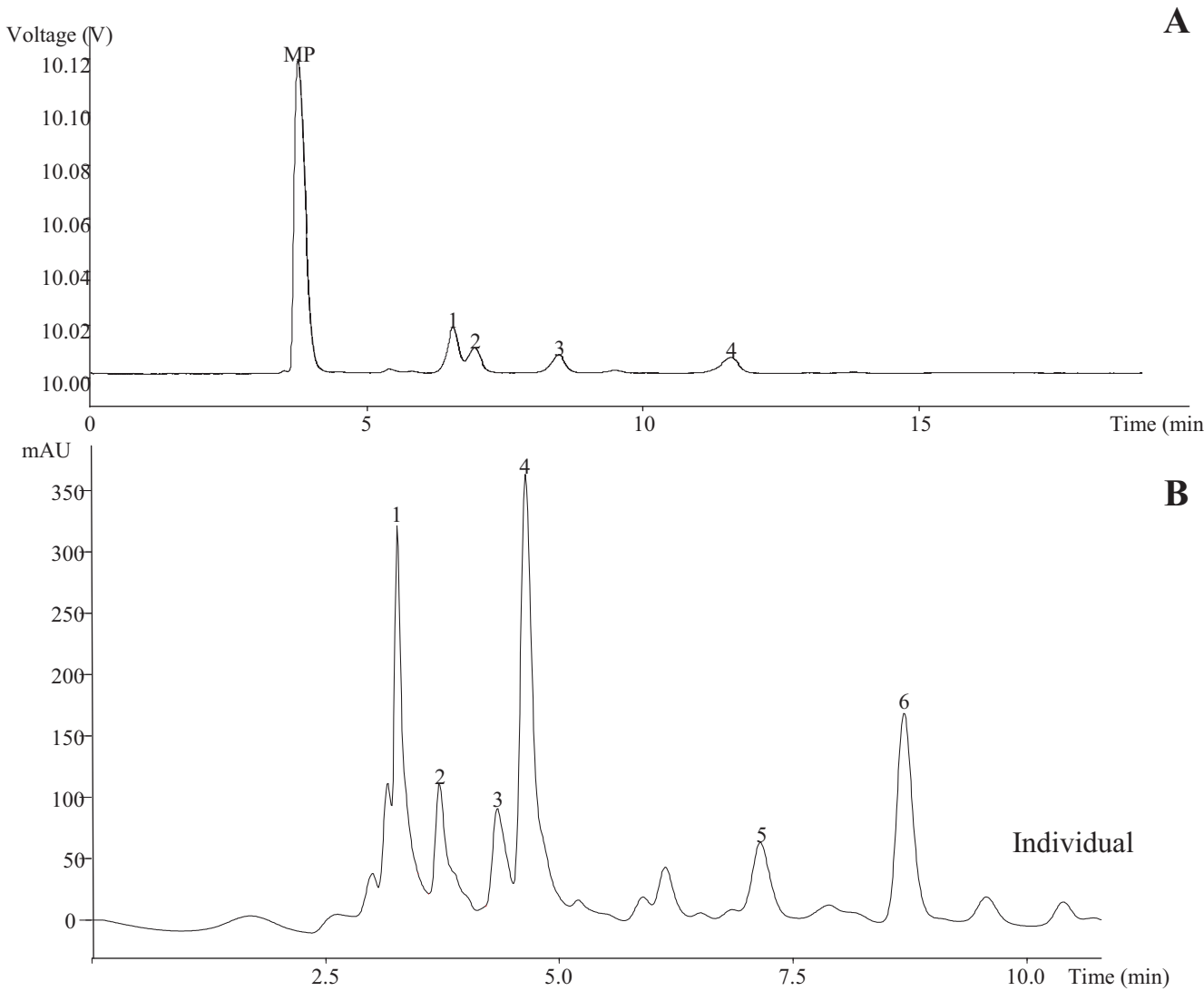

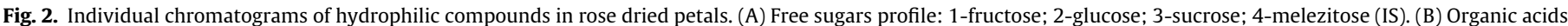
profile: 1-oxalic acid; 2-quinic acid; 3-malic acid; 4-shiquimic acid; 5-citric acid; 6-fumaric acid. MP-mobile phase.

and infusions $(0.19 \mathrm{~g} / 100 \mathrm{ml}$ of infusion) gave the highest total sugars amount, while centaurea dried petals $(1.5 \mathrm{~g} / 100 \mathrm{~g} \mathrm{dw})$ and infusion $(0.14 \mathrm{mg} / 100 \mathrm{ml})$ presented the lowest levels of total sugars. Fructose, glucose and sucrose were detected in the dried petals and infusions, being fructose the main sugar present in dahlia and rose samples; with the exception of calendula dry petals and centaurea infusion, where sucrose was predominant. This is in accordance with the results reported by Barros et al. (2011) in
$R$. canina. petals, in which fructose was also the main sugar. On the other hand, Dias et al. (2014) reported higher amounts of sugars in flowers of dandelion, despite having a similar profile (fructose, glucose and sucrose). Nonetheless, this tendency was not observed in C. officinalis samples analysed by Miguel et al. (2016), where fructose was the main sugar detected, followed by sucrose and xylose. Currently, EFSA does not have a recommended daily dose for sugars intake, since the data on the matter is 
insufficient to set an upper limit of consumption for these compounds (EFSA, 2010a). Nonetheless, WHO recommends the reduce of free sugars intake to be less than $10 \%$ of total energy intake in a normal daily diet (Brouns, 2015). However, the studied flowers can be used "in" and "as" foods and contribute for sugar's daily intake.

Regarding the organic acids profile, the studied samples presented very distinct profiles (Table 2). The highest amount of organic acids was found in rose dried petals, mainly due to the presence of quinic and malic acids (1.53 and $1.23 \mathrm{~g} / 100 \mathrm{~g} \mathrm{dw}$, respectively). Among the infusions, calendula and centaurea presented the highest concentrations, mainly due to the presence of quinic $(14.5 \mathrm{mg} / 100 \mathrm{ml})$ and citric acids $(15.5 \mathrm{mg} / 100 \mathrm{ml})$, respectively. The dried petals of calendula also presented high amounts of organic acids, mainly due to the contribution of malic and succinic acids ( 1.14 and $1.77 \mathrm{~g} / 100 \mathrm{~g}$ dw, respectively). The presence of high quantities of malic acid was also detected in C. officinalis flowers by Miguel et al. (2016), however the presence of succinic acid was not reported, while citric acid was the main organic acid. The same tendency was also described by Dias et al. (2014) in flowers of dandelion, where malic acid was the most abundant one, showing also the highest level of total organic acids. Fumaric acid was only found in trace amounts in the analysed dahlia and centaurea dried petals. Dahlia revealed the lowest content of organic acids, presenting only traces of oxalic and shiquimic acids.

\subsection{Lipophilic compounds of edible petals}

The content in lipophilic compounds, namely fatty acids and tocopherols, was determined in the dried petals and the results are shown in Table 3 and Fig. 3. Twenty-four fatty acids were identified, being polyunsaturated fatty acids (PUFA) predominant in all the samples, with the exception of dahlia that showed higher concentration of saturated fatty acids (SFA). Linoleic acid (C18:2n6) was the major fatty acid found in dahlia and rose samples (36.54 and $31.87 \%$, respectively), followed by palmitic acid (C16:0) and linolenic acid (C18:3n3), respectively. Calendula presented linolenic acid $(36.90 \%)$ as the main fatty acid, followed by palmitic acid (21.70\%), while centaurea presented eicosapentaenoic acid (C20:5n3, 26.93\%) as the main fatty acid, followed by linolenic acid (18.75\%). The results found for $C$. officinalis are in accordance with the ones described by Dulf et al. (2013) in which PUFA content is around $60-64 \%$, and the saturated fraction is mainly consisted by palmitic acid. The same tendency was not reported by Miguel et al. (2016) in calendula samples, that presented a SFA fraction much higher than the PUFA fraction (78\% and 21\%, respectively). According with the recommendations of EFSA, the recommended daily intake of SFA is the lowest possible (EFSA, 2010b), and therefore, calendula edible flowers are good options presenting the lowest content of SFA. On the other hand, it is recommended a daily intake of $4 \%$ of the total dietary energy in linoleic acid and

Table 3

Fatty acids and tocopherols composition in dried petals (mean $\pm \mathrm{SD}$ ).

\begin{tabular}{|c|c|c|c|c|}
\hline & Dahlia & Rose & Calendula & Centaurea \\
\hline \multicolumn{5}{|c|}{ Fatty acids (relative percentage, \%) } \\
\hline $\mathrm{C} 6: 0$ & $0.89 \pm 0.07$ & $0.18 \pm 0.01$ & $0.27 \pm 0.01$ & $0.17 \pm 0.01$ \\
\hline $\mathrm{C} 8: 0$ & $0.90 \pm 0.09$ & $0.23 \pm 0.02$ & $0.28 \pm 0.06$ & $0.07 \pm 0.00$ \\
\hline C10:0 & $0.99 \pm 0.04$ & $0.33 \pm 0.05$ & $0.18 \pm 0.08$ & $0.12 \pm 0.00$ \\
\hline $\mathrm{C} 11: 0$ & nd & nd & $0.13 \pm 0.03$ & nd \\
\hline C12:0 & $0.74 \pm 0.03$ & $1.22 \pm 0.05$ & $1.65 \pm 0.18$ & nd \\
\hline C13:0 & nd & $0.03 \pm 0.00$ & nd & nd \\
\hline C14:0 & $3.11 \pm 0.20$ & $2.55 \pm 0.14$ & $9.92 \pm 0.39$ & $0.89 \pm 0.05$ \\
\hline C14:1 & $0.59 \pm 0.03$ & $0.31 \pm 0.00$ & nd & $0.21 \pm 0.02$ \\
\hline C15:0 & $0.66 \pm 0.00$ & $0.31 \pm 0.01$ & $0.18 \pm 0.01$ & $0.37 \pm 0.01$ \\
\hline C16:0 & $24.61 \pm 0.77$ & $17.10 \pm 1.06$ & $21.70 \pm 0.10$ & $15.40 \pm 0.10$ \\
\hline C16:1 & $0.87 \pm 0.00$ & $0.22 \pm 0.00$ & $0.23 \pm 0.03$ & $0.28 \pm 0.02$ \\
\hline $\mathrm{C} 17: 0$ & $0.91 \pm 0.09$ & $0.53 \pm 0.04$ & $0.19 \pm 0.04$ & $0.82 \pm 0.02$ \\
\hline C18:0 & $7.60 \pm 0.28$ & $16.80 \pm 0.27$ & $3.95 \pm 0.08$ & $9.67 \pm 0.08$ \\
\hline C18:1n9 & $5.75 \pm 0.08$ & $1.95 \pm 0.19$ & $1.56 \pm 0.06$ & $4.41 \pm 0.04$ \\
\hline C18:2n6 & $36.54 \pm 0.85$ & $31.87 \pm 0.33$ & $20.35 \pm 0.14$ & $6.72 \pm 0.08$ \\
\hline $\mathrm{C} 18: 3 \mathrm{n} 3$ & $8.60 \pm 0.56$ & $19.54 \pm 0.79$ & $36.90 \pm 0.55$ & $18.75 \pm 0.14$ \\
\hline C20:0 & $1.57 \pm 0.08$ & $3.62 \pm 0.03$ & $0.63 \pm 0.02$ & $5.34 \pm 0.05$ \\
\hline C20:2 & $0.40 \pm 0.03$ & nd & nd & nd \\
\hline$C 20: 3 n 3$ & $0.63 \pm 0.10$ & $0.33 \pm 0.00$ & $0.26 \pm 0.01$ & $0.51 \pm 0.08$ \\
\hline C20:5n3 & nd & nd & nd & $26.93 \pm 0.29$ \\
\hline C22:0 & $2.15 \pm 0.19$ & $1.81 \pm 0.13$ & $0.56 \pm 0.04$ & $2.04 \pm 0.00$ \\
\hline C22:1n9 & nd & nd & nd & $6.01 \pm 0.12$ \\
\hline C23:0 & $0.21 \pm 0.02$ & $0.08 \pm 0.01$ & $0.13 \pm 0.03$ & $0.15 \pm 0.00$ \\
\hline $\mathrm{C} 24: 0$ & $2.31 \pm 0.01$ & $1.01 \pm 0.07$ & $0.93 \pm 0.09$ & $1.14 \pm 0.10$ \\
\hline SFA & $46.64 \pm 1.46 a$ & $45.79 \pm 1.30 \mathrm{~b}$ & $40.70 \pm 0.70 c$ & $36.18 \pm 0.28 d$ \\
\hline MUFA & $7.20 \pm 0.11 b$ & $2.47 \pm 0.19 c$ & $1.79 \pm 0.02 d$ & $10.91 \pm 0.13 a$ \\
\hline PUFA & $46.16 \pm 1.35 d$ & $51.74 \pm 1.11 c$ & $57.51 \pm 0.68 a$ & $52.91 \pm 0.15 b$ \\
\hline \multicolumn{5}{|c|}{ Tocopherols (mg/100 g dw) } \\
\hline$\alpha$-Tocopherol & $4.36 \pm 0.07 c$ & $8.16 \pm 0.08 b$ & $56.78 \pm 1.06 a$ & $0.55 \pm 0.02 d$ \\
\hline$\beta$-Tocopherol & $1.77 \pm 0.01 \mathrm{a}$ & $0.18 \pm 0.01 c$ & $1.16 \pm 0.06 b$ & nd \\
\hline$\gamma$-Tocopherol & $0.72 \pm 0.02 b$ & $0.77 \pm 0.01 b$ & $2.94 \pm 0.08 a$ & $0.29 \pm 0.02 c$ \\
\hline$\delta$-Tocopherol & $0.43 \pm 0.01 a$ & $0.14 \pm 0.01 b$ & nd & nd \\
\hline Sum & $7.28 \pm 0.04 c$ & $9.25 \pm 0.04 b$ & $60.88 \pm 0.92 a$ & $0.84 \pm 0.04 \mathrm{~d}$ \\
\hline
\end{tabular}

dw - dry weight basis; nd - not detected. C6:0 - Caproic acid; C8:0 - Caprylic acid; C10:0 - Capric acid; C11:0 - Undecylic acid; C12:0 - Lauric acid; C13:0 - Tridecanoic acid; C14:0 - Myristic acid; C14:1 - Myristoleic acid; C15:0 - Pentadecanoic acid; C16:0 - Palmitic acid; C16:1 Palmitoleic acid; C17:0 - Heptadecanoic acid; C18:0 - Stearic acid; C18:1n9 - Oleic acid; C18:2n6 - Linoleic acid; C18:3n3 - Linolenic acid; C20:0 - Arachidic acid; C20:2 - cis-11,14 - Eicosadienoic acid; C20:3n3 - Eicosatrienoic acid; C20:5n3 - Eicosapentaenoic acid; C22:0 - Behenic acid; C22:1n9 - Erucic acid; C23:0 - Tricosanoic acid; C24:0 - Lignoceric acid. SFA - saturated fatty acids, MUFA - monounsaturated fatty acids, PUFA polyunsaturated fatty acids. In each row different letters mean significant differences between samples ( $\mathrm{p}<0.05)$, where "a" and "d" correspond to the highest and lowest values, respectively. 


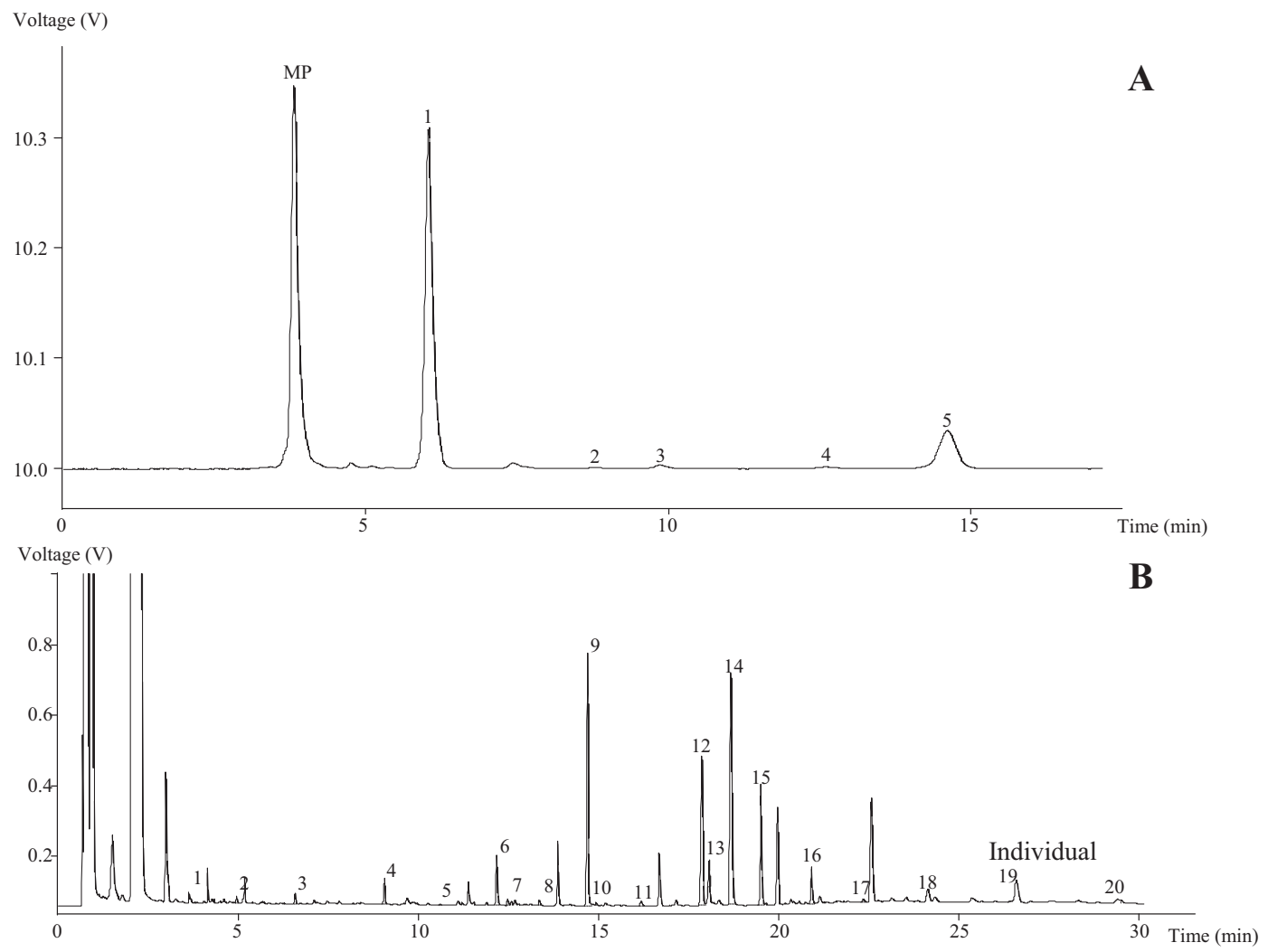

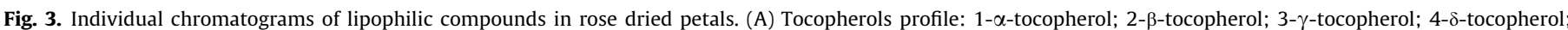

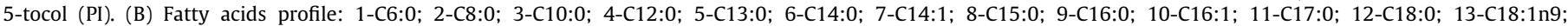
14-C18:2n6; 15-C18:3n3; 16-C20:0; 17-C20:3n3; 18-C22:0; 19-C23:0; 20-C24:0. MP-mobile phase.

also the presence of eicosapentaenoic acid (C20:5n3), especially for pregnant women (EFSA, 2010b); only centaurea samples presented this last compound. For PUFA intake, WHO recommends more than $15 \%$ of the total dietary intake for infants (0-24 months) and $11 \%$ of the total dietary intake for children ( $2-18$ years) (World Health Organization, 2008).

Regarding tocopherols, $C$. officinalis was the sample that revealed the highest content $(60.88 \mathrm{mg} / 100 \mathrm{~g} \mathrm{dw})$, mainly due to the presence of $\alpha$-tocopherol isoform $(56.78 \mathrm{mg} / 100 \mathrm{~g} \mathrm{dw}$ ). Miguel et al. (2016) also described $\boldsymbol{\alpha}$-tocopherol as the main isoform in calendula flowers, however, the authors described lower values of total tocopherols. In all the samples, $\alpha$-tocopherol isoform appears in higher amounts than the remaining isoforms. $\beta$ - and $\delta$-Tocopherols were not detected in centaurea, being the latter isoform also not present in calendula. The daily recommended dose for tocopherols consumption in adults is $300 \mathrm{mg} /$ day (EFSA, 2008). Despite the lower values of the studied samples, the daily consumption of edible flowers could contribute to supply this vitamin to the organism.

Overall, calendula petals gave the highest content in total fat, ash and energetic contribution, polyunsaturated fatty acids (mainly due to the presence of linolenic acid) and total tocopherols (with the major contribution of $\alpha$-tocopherol). On the other hand, rose petals presented the highest values of total proteins, soluble sugars and organic acids. Centaurea presented the highest carbohydrates content and the lowest percentage of saturated fatty acids. Regarding the infusions, dahlia and rose showed the highest content in carbohydrates, and the latter the highest energetic contribution. Calendula infusion presented the highest content in sugars, while the highest content in organic acids was found in centaurea infusion. These results demonstrate that edible petals can be consumed in a daily diet as a nutrient source, and could also be used to prepare infusions to be consumed worldwide.

\section{Acknowledgements}

We thank the Foundation for Science and Technology (FCT, Portugal) and also thank FEDER under Program PT2020 for financial support to CIMO (UID/AGR/00690/2013), LSRE (Project UID/EQU/50020/2013), L. Barros (SFRH/BPD/107855/2015) and I. Dias (SFRH/BD/84485/2012) grants. The authors are also grateful to Prof. Carlos Aguiar (CIMO) for systematic identification of the studied species.

\section{References}

AOAC (2005). In G. L. W. Horwitz (Ed.), Official methods of analysis of AOAC international (18th ed.. Gaithersburg: AOAC International.

Barros, L., Carvalho, A. M., \& Ferreira, I. C. F. R. (2011). Exotic fruits as a source of important phytochemicals: Improving the traditional use of Rosa canina fruits in.

Barros, L., Pereira, C., \& Ferreira, I. C. F. R. (2013). Optimized analysis of organic acids in edible mushrooms from Portugal by ultra fast liquid chromatography and photodiode array detection. Food Analytical Methods, 6(1), 309-316.

Barros, L., Pereira, E., Calhelha, R. C., Dueñas, M., Carvalho, A. M., Santos-Buelga, C., et al. (2013). Bioactivity and chemical characterization in hydrophilic and lipophilic compounds of Chenopodium ambrosioides L. Journal of Functional Foods, 5(4), 1732-1740.

Brouns, F. (2015). WHO Guideline: "Sugars intake for adults and children" raises some question marks. Agro Food Industry Hi-Tech, 26(4), 34-36.

Cunningham, E. (2015). What nutritional contribution do edible flowers make? Journal of the Academy of Nutrition and Dietetics, 115(5), 856

Dias, M. I., Barros, L., Alves, R. C., Oliveira, M. B. P. P., Santos-Buelga, C., \& Ferreira, I. C. F. R. (2014). Nutritional composition, antioxidant activity and phenolic compounds of wild Taraxacum sect. Ruderalia. Food Research International, 56, 266-271. 
Dulf, F. V., Pamfil, D., Baciu, A. D., \& Pintea, A. (2013). Fatty acid composition of lipids in pot marigold (Calendula officinalis L.) seed genotypes. Chemistry Central Journal, 7(1), 8

EFSA (2008). Opinion on mixed tocopherols, tocotrienol tocopherol and tocotrienols as sources for vitamin $\mathrm{E}$ added as a nutritional substance in food. Scientific opinion of the panel on food additives, flavourings, processing aids and materials in contact with food. The EFSA Journal, 604, 1-34.

EFSA (2010a). Scientific opinion on dietary reference values for carbohydrates and dietary fibre. EFSA Journal, 8(3), 1-77.

EFSA (2010b). Scientific opinion on dietary reference values for fats, including saturated fatty acids, polyunsaturated fatty acids, monounsaturated fatty acids, trans fatty acids, and cholesterol. EFSA Journal, 8(3), 1461.

Falguera, V., Aliguer, N., \& Falguera, M. (2012). An integrated approach to current trends in food consumption: Moving toward functional and organic products? Food Control, 26(2), 274-281.

Kelley, K. M., Behe, B. K., Biernbaum, J. A., \& Poff, K. L. (2001). Consumer ratings of edible flower quality, mix, and color. HortTechnology, 11(4), 644-647.

Koike, A., Barreira, J. C. M., Barros, L., Santos-Buelga, C., Villavicencio, A. L. C. H., \& Ferreira, I. C. F. R. (2015). Edible flowers of Viola tricolor L. as a new functional food: Antioxidant activity, individual phenolics and effects of gamma and electron-beam irradiation. Food Chemistry, 179, 6-14.

Lara-Cortés, E., Martín-Belloso, O., Osorio-Díaz, P., Barrera-Necha, L. L., SánchezLópez, J. A., \& Bautista-Baños, S. (2014). Antioxidant capacity nutritional and functional composition of edible dahlia flowers. Revista Chapingo Serie Horticultura, XX (1), 101-116.

Leonti, M. (2012). The co-evolutionary perspective of the food-medicine continuum and wild gathered and cultivated vegetables. Genetic Resources and Crop Evolution, 59(7), 1295-1302.

Loizzo, M. R., Pugliese, A., Bonesi, M., Tenuta, M. C., Menichini, F., Xiao, J., et al. (2016). Edible flowers: a rich source of phytochemicals with antioxidant and hypoglycemic properties. Journal of Agricultural and Food Chemistry, 64(12), 2467-2474.

Lu, B., Li, M., \& Yin, R. (2016). Phytochemical content, health benefits, and toxicology of common edible flowers: A review (2000-2015). Critical Reviews in Food Science and Nutrition, 56(Suppl 1), S130-S148.

Łuczaj, Ł., Pieroni, A., Tardío, J., Pardo-de-Santayana, M., Sõukand, R., Svanberg, I., et al. (2012). Wild food plant use in 21st century Europe: The disappearance of old traditions and the search for new cuisines involving wild edibles. Acta Societatis Botanicorum Poloniae, 81(4), 359-370.

Miguel, M., Barros, L., Pereira, C., Calhelha, R. C., Garcia, P. A., Castro, M. Á., et al. (2016). Chemical characterization and bioactive properties of two aromatic plants: Calendula officinalis L. (flowers) and Mentha cervina L. (leaves). Food E Function, 7(5), 2223-2232.

Mlcek, J., \& Rop, O. (2011). Fresh edible flowers of ornamental plants - A new source of nutraceutical foods. Trends in Food Science and Technology, 22(10), 561-569.

Navarro-González, I., González-Barrio, R., García-Valverde, V., Bautista-Ortín, A. B., \& Periago, M. J. (2015). Nutritional composition and antioxidant capacity in edible flowers: Characterisation of phenolic compounds by HPLC-DAD-ESI/MSn. International Journal of Molecular Sciences, 16(1), 805-822.

Pereira, C., Barros, L., \& Ferreira, I. C. F. R. (2015). A Comparison of the nutritional contribution of thirty-nine aromatic plants used as condiments and/or herbal infusions. Plant Foods for Human Nutrition, 70(2), 176-183.

Rop, O., Mlcek, J., Jurikova, T., Neugebauerova, J., \& Vabkova, J. (2012). Edible flowers-A new promising source of mineral elements in human nutrition. Molecules, 17(12), 6672-6683.

World Health Organization (2008). Fats and fatty acids in human nutrition, report of an expert consultation (Vol. 91) Food and Nutrition Paper: FAO. 